\title{
Behandling vid upprepad självskada och suicidförsök hos tonåringar: en planerad, randomiserad och kontrollerad multicenterstudie
}

\author{
Vid Bo Larsson, Berit Grøholt och Lars Mehlum
}

\section{Förekomst av självskadande beteende eller suicidförsök bland tonåringar}

Avsiktlig självskada eller suicidförsök är viktiga hälsoproblem och rapporteras av c:a 3-11 \% av tonåringar i Skandinavien och i internationella studier (Wichström 2000; Gould et al., 2003; Ystgaard et al., 2003). Prevalensen ökar i förekomst under hela tonårsperioden, särskilt i åldrarna 15-19 år. Under tonårsperioden tar pojkar oftare sitt liv än flickor, medan flickorna gör c:a 2-4 gånger fler suicidförsök (Lewinsohn, Rohde \& Seeley, 1996; Groholt et al., 2000). Många tonåringar upprepar också suicidförsöken, särskilt den närmaste tiden efter ett försök (Brent et al., 1993). Bland tonåringar som läggs in på sjukhus efter självmordsförsök har flertalet överdoserat med mediciner. Undersökningar av tonåringar i normalpopulation har emellertid visat att den vanligaste formen av avsiktligt självskadande beteende är att skära sig med vasst föremål (60-75\%), medan överdosering med läkemedel förekommer bland c:a 25-40\% i denna problemgrupp (Ystgaard et al., 2003, Rodham et al., 2004). I en stor europeisk multicenterstudie fann man att endast en liten andel (12-15\%) av de skolungdomar som självskadat sig avsiktligt under sista året hade blivit hänvisade eller sökt hjälp på sjukhus (Ystgaard et al., 2003; Rodham et al., 2004). Man fann också en högre andel tonåringar med suicidintention bland de som överdoserat farmaka än de som skurit sig. De yngre åldersgrupperna är starkt

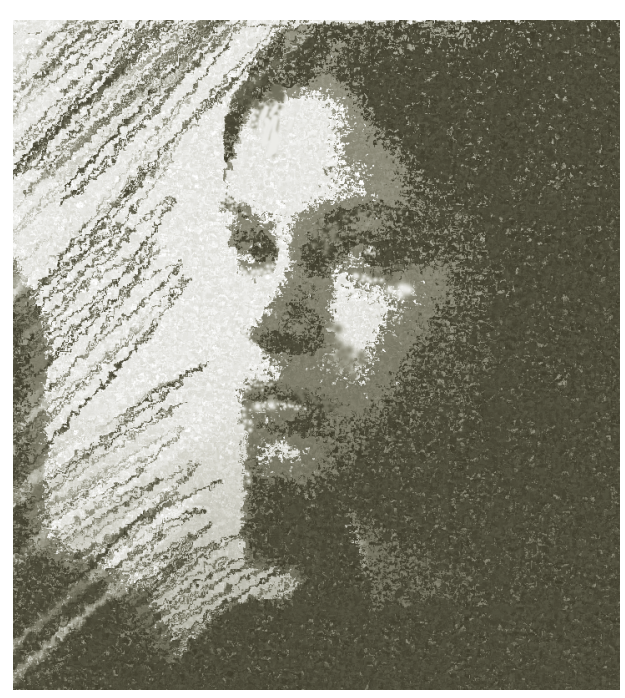

överrepresenterade bland patienter som läggs in på somatisk sjukhus efter självmordsförsök. Till BUP remitteras c.a 4\% av patienter årligen på grund av suicidmisstanke (BUP-data, 2005). Tidigare självmordsförsök är också en av de viktigaste riskfaktorerna för fullbordat suicid och kräver därför särskild uppmärksamhet i omhändertagandet i hälso- och sjukvården.

\section{Empirisk behandlingsforskning}

Förvånansvärt få patienter som gjort suicidförsök hänvisas dock till barn- och ungdomspsykiatrin för uppföljning och eftervård och bland dessa avbryter alltför många behandlingen i förtid (Rathus \& Miller, 2002; Piacentini et al., 1995).

Barriärerna består inte bara av individeller familje-relaterade orsaker utan finns också i sjukvårdssystemet i form av väntetider eller problem med tidbokning (Spirito et al., 2002). I en amerikansk studie fann man att en snabb påbörjad kontakt, som etablerats redan i akutrummet med tonåringar efter suicidförsök och deras föräldrar, gav bättre genomförd poliklinisk behandling för tonåringar (Rotheram-Borus et al., 1995). I en liknande studie noterades förbättrad följsamhet i poliklinisk behandling 3 månader efter suicidförsök bland tonåringar (majoriteten hade överdoserat med tabletter) (Spirito et al., 2002). Författarna poängterade att de största hindren för individen och familjen var relaterade till begränsningar i vårdsystemet.

Kunskapen idag om effekter av hospitalisering för barn eller ungdomar som gjort suicidförsök är nästan obefintlig. I en quasiexperimentell studie nyligen genomförd i Canada fann man att dialektisk beteendeterapi (DBT) administrerad till ungdomar vårdade på psykiatrisk klinik under c:a 2 veckor efter suicidförsök eller allvarliga självmordstankar, reducerade antalet självskador och inicidenter redan på avdelningen i jämförelse med psykodynamisk terapi (Katz et al., 2004). Av betydelse är också att alla patienter som behandlats med DBT fullföljde kontakten under uppföljning i poliklinisk behandling. Ett familjefokuserat behandlingsprogram, som utvecklats av Harrington och medarbetare i Manchester för suicidala tonåringar omfattar fem sessioner, som administrerades i hemmet (Harrington, 2000). Programmet minskade suicidtankar hos tonåringar utan depression, men inga skillnader mellan behandlingsgrupperna observerades för tonåringar med depression eller upprepning av självskadande beteende. Författarna konkluderar att fem sessioner i behandlingen av suicidala tonåringar från familjer med kommunikationsproblem och hög interpersonell stress är otillräckliga och att mer intensiv och längre tids behandling sannolikt är nödvändig.

Samma forskargrupp har publicerat resultat från en studie, där behandling i grupp givits till tonåringar (12-16 år), som gjort minst två tidigare suicidförsök eller självskadat sig utan suicidintention (Wood et al., 2001). Denna gruppbehandling som tillägg till sedvanlig behandling ("routine treatment") i barnpsykiatrin minskade risken för ny självskada, liksom skolfrånvaro, användning av rutinsjukvård, men också beteendeproblem hos tonåringen. Nyligen har effekter utvärderats av en mer intensiv, hembaserad familjeintervention (Multisystemic therapy-MST), administrerad under 3-6 månader till ungdom och deras familjer, men som också fokuserar på problem i andra miljöer, t ex i skola eller på fritid. (Huey et al., 2004). I en jämförelse med hospitalisering minskade behandling med MST risken för upprepad självskada under ett års uppföljning, men inga positiva effekter noterades på depressiva symtom, hopplöshetskänslor eller suicidtankar.

Rathus \& Miller (2002) i New York har också publicerat preliminära resultat från en jämförelse mellan "treatment as usual" (TAU) och en DBT version, som anpassats för tonåringar som avsiktligt självskadat sig eller gjort suicidförsök. Denna version av DBT, som utvecklats av Linehan för suicidala kvinnor med borderline personlighetsstörning, reducerade hospitalisering av tonåringar under behandlingen och signifikant flera av dem fullföljde behandlingen än de som behandlats med TAU. DBT minskade också suicidtankar, depression och ångestsymtom, men ingen skillnad mellan de två behandlingsgrupperna observerades för upprepade suicidförsök under den korta uppföljningstiden. 


\section{Nationell interventionsstudie}

$M$ ot bakgrund av dokumentation från empirisk forskning och att DBT redan används inom barn- och ungdomspsykiatrin (både i N orge och i Sverige) planeras nu en randomiserad och kontrollerad studie med syfte att utvärdera effekterna av DBT för tonåringar som avsiktligt självskadat sig (Rathus \& M iller, 2002) $i$ en jämförelse med vanlig behandling (treatment-as usual). Projektet har redan fătt ekonomiskt stöd av Sosial- og helsedirektoratet i 0 slo. D et genomförs av Seksjon for selvmordsforskning og -forebygging, U niversitetet i 0 slo i samarbete med Senter for psykisk helse, Sogn,

N OVA, Folkehelseinstituttet i O slo och Region senter for barn og unges psykiske helse, N T N U, Trondheim.

I projektet inkluderas tonåringar i ålder 13-19 år, som under senaste året avsiktligt självskadat sig vid minst två tillfällen med eller utan suicidintention. Behandlingen genomförs vid BU P polikliniker på tre orter: 0 sl 0 , Trondheim och Bergen. Tonåringar med akut psykos, anorexia nervosa, A spergers syndrom, mental retardation eller med flyktingstatus ska exkluderas. Totalt beräknas c:a 140 tonåringar ingå i studien, hälften får DBT och de andra får vanlig behandling $i$ barnpsykiatrin. Bortfallet under behandling uppskattas till c:a 20-25\%.

Patienterna rekrytteras efter akut vård på somatisk avdelning eller barn psykiatrisk klinik, men också från primärvården (allmänläkare och skolhälsovården). Tonåringar och deras föräldrar kontaktas snarast möjligt av ansvarig person i prosjektet (1-2 dygn efter självskadehandlingen). D e som ställer sig positiva till erbjudandet randomiseras efter noggrann och systematisk evaluering till en av behandlingsgrupperna. De två olika behandlingsmetoderna administreras separat på BU P polikliniker av tränade DBT terapeuter under handledning eller av terapeuter som genomför psykoterapeutisk behandling enl. sedvanlig praxis. Innehållet $\mathrm{i}$ båda behan dlingsmodellerna dokumenteras bl.a. med ljudband och evalueras kontinuerligt. Bedömning av behov av farmakabehandling, $t$ ex med SSRI vid depression görs kontinuerligt i projektet under behandlingsfasen. Beslut om medicinering följer särskilt behand- lingsprotokoll och fattas av ansvarig barn psykiater på respektive ort.

I utvärderingen av individ och familj ingår semistrukturerade intervjuer (K-SA DS för psykiatrisk diagnos och komorbiditet; personlighetsfaktorer) som genomförs av oberoende intervjuare i projektet. Information kommer också att inhämtas med hjälp av standardiserade frågeformulär som fokuserar på suicidal itet hos individ och familj, emotionella och beteen deproblem, stressfaktorer, sexuella och fysiska övergrepp, relationer till familj och kamrater, familje- och skoltrivsel, mobbing.

Primära effektkriterier i studien är reduktion av självskadande beteende med eller utan suicidintention under ett års uppföljning. Långtidsuppföljning planeras också ( 3 år senare). Prediktorer relaterade till positiva eller negativa resultat av behandlingen ingår i de planerade analyserna liksom skillnader mellan patientgrupperna och kostnadseffektiva aspekter, t ex kostnader för hospitalisering och medicinering.

Resultatet av projektet förväntas få stor nationell betydelse för han dläggningen och omhändertagan det i klinisk praxis och utvecklingen av effektiva och evidensbaserade behandlingsmetoder för en viktig problemgrupp i barn- och ungdomspsykiatrin.

B o L arsson er professor i barne- og ungdomspsykiatri og er tilknyttet Seksjon for selvmordsforskning og -forebygging, U niversitetet i 0 slo og Regionsenter for barn og unges psykiske hel se, NTNU, Trondheim.

B erit G røholt er professor i psykiatri og er ansatt ved Senter for psykisk helse - barn og ungdom, forskningsen heten, Sogn, 0 slo.

Lars M ehlum er professor i er professor i suicidologi og psykiatri og leder for Seksjon for selvmordsforskning og -forebygging, U niversitetet i 0 slo.

\section{Referenser}

Brent $D, K$ olko DJ, W artella $M$ et al. A dolescent psychiatric inpatients' risk of suicide attempt at six-month follow-up. J A $\mathrm{m} \mathrm{A}$ cad $C$ hild $A$ dolesc Psychiatry. 1993; 32:95-105.

BU P data. N orsk forening for barne- og ungdompsykiatriske institusjoner. 2005.
G ould M S, G reen berg T, Velting DM, Shaffer D. Youth suicide risk and preventive interventions: a review of the past 10 years. J A $\mathrm{m} \mathrm{A}$ cad $\mathrm{C}$ hild A dolesc Psychiatry 2003; 42(4):386-405.

G roholt B, Ekeberg $O$, Wichstrom $L, H$ aldorsen $T$. Young suicide attempters: a comparison between a clinical and an epidemiological sample. J A m A cad Child A dol esc Psychiatry. 2000; 39(7):868-75.

$H$ arrington $R, K$ erfoot $M$, Dyer $E, M C N$ iven $F$, Gill J, H arrington V, W oodham A. D eliberate self-poisoning in adolescence: why does a brief family intervention work in some cases and not others? J A dolesc 2000; 23(1):13-20.

H uey S, H enggeler SW, Rowland M D, H all idayBoykins C A, C unningham PB, Pickrel SG Edwards J. Multisystemic therapy effects on attempted suicide by youths presenting psychiatric emergencies. J A m A cad Child A dolesc Psychiatry 2004; 43(2):183-190.

Katz LY, C ox BJ, G unasekara S, M iller A L. Feasibility of dialectical behavior therapy for suicidal adolescent inpatients. J A $m$ A cad Child A dolesc Psychiatry 2004; 43(3):276-282.

Lewinsohn P, R ohde P, Seely JR. A dolescent suicide ideation and attempts: prevalence, risk factors, and clinical implications. Clin Psychol: Sci Pract 1996; 3: 25-46.

Piacentini J, Rotheram-Borus M J, Gillis JR, G raae F, Trautmann P, C antwell C, G arcia-Leeds C Shaffer D. D emographic predictors of treatment attendance among adolescent suicide attempters. J Consult Clin Psychol 1995; 63 (3):469-473.

Rathus JH, M iller A L. D ialectic behavior therapy adapted for suicidal adolescents. Suic Life T hreat Behav 2002; 32: 146-157.

Rodham K, H awton K, Evans E. R easons for deliberate self-harm: comparison of self-poisoners and self-cutters in a community sample of adolescents. J A $\mathrm{m} \mathrm{A}$ cad $C$ hild $\mathrm{A}$ dolesc Psychiatry 2004; 43(1):80-87.

Rotheram-Borus M J, Piacentini J, M iller S, G raae $\mathrm{F}, \mathrm{C}$ astro-Blanco D. B rief cognitive-behavioral treatment for adolescent suicide attempters and their families. J A $m$ A cad Child A dolesc Psychiatry 1995; 33(4):508-517.

Spirito A, Boergers J, D onaldson D, Bishop D, Lewander W. A $\mathbf{n}$ intervention trial to improve adherence to community treatment by adolescents after a suicide attempt. A $\mathrm{m} \mathrm{A}$ cad $C$ hild $A$ dolesc Psychiatry 2002; 41(4):435-442.

W ichstrom L. Predictors of adolescent suicide attempts: a nationally representative longitudinal study of $\mathbf{N}$ orwegian adolescents. J A $\mathrm{m} \mathrm{A}$ cad Child A dolesc Psychiatry 2000; 39(5):603-610.

Wood A, Trainor G, Rothwell J, M oore A, $H$ arrington R. R andomized trial of group therapy for repeated deliberate self-harm in adolescents. J A m A cad Child A dolesc Psychiatry 2001; 40(11):1246-1253.

Ystgaard M, Reinholdt N P, H usby J, M ehlum L. Villet selvskade blant ungdom. Tidsskr $N$ or Lægeforen 2003; 123: 2241-5. 